\title{
OBJECT BASED BUILDING EXTRACTION AND BUILDING PERIOD ESTIMATION FROM UNMANNED AERIAL VEHICLE DATA
}

\author{
R. Comert ${ }^{1}$, O. Kaplan ${ }^{2 *}$ \\ ${ }^{1}$ Department of Geomatics Engineering, Faculty of Engineering and Natural Sciences, Gumushane University, Gumushane, Turkey \\ (rcomert@gumushane.edu.tr) \\ ${ }^{2}$ Earth and Space Sciences Institute, Anadolu University 26555 Eskisehir, Turkey (onur_kaplan@anadolu.edu.tr)
}

KEY WORDS: Building Period, Building Height, UAV, Object-Based Image Analysis

\begin{abstract}
:
The aim of this study is to examine whether it is possible to estimate the building periods with respect to the building heights in the urban scale seismic performance assessment studies by using the building height retrieved from the unmanned aerial vehicle (UAV) data. For this purpose, a small area, which includes eight residential reinforced concrete buildings, was selected in Eskisehir (Turkey) city center. In this paper, the possibilities of obtaining the building heights that are used in the estimation of building periods from UAV based data, have been investigated. The investigations were carried out in 3 stages; (i) Building boundary extraction with Object Based Image Analysis (OBIA), (ii) height calculation for buildings of interest from nDSM and accuracy assessment with the terrestrial survey. (iii) Estimation of building period using height information. The average difference between the periods estimated according to the heights obtained from field measurements and from the UAV data is $2.86 \%$ and the maximum difference is $13.2 \%$. Results of this study have shown that the building heights retrieved from the UAV data can be used in the building period estimation in the urban scale vulnerability assessments.
\end{abstract}

\section{INTRODUCTION}

The determination of the fundamental vibration period of a building is essential for both earthquake design and seismic vulnerability assessment. The building period is dependent on the mass and the stiffness of the building (Salameh et al. 2016) and it can be computed by eigenvalue or pushover analyses, which are conducted to a numerical model of the building. However, when conducting seismic vulnerability assessment studies in urban scale, it is necessary to estimate the seismic performance of hundreds or thousands of buildings (Crowley and Pinho 2004). Obviously, carrying out computer analysis to determine the vibration period of each building, present in the considered urban area is not feasible. Therefore, simplified equations to estimate the building period with respect to building height can be used instead. In many seismic design codes, there are empirical and semiempirical equations, which can be used to estimate the building period according to building height (Goel and Chopra 1997), which is a key factor for the building period estimation. Measuring the height of each building in large building stocks with traditional field survey methods can be very time-consuming. Therefore, it is necessary to use innovative technologies like remote sensing applications for determining building height (Masi and Vona 2009).

Remote sensing offers many opportunities to obtain information on urban areas such as monitoring urban development and detection land use and land cover changes (Li et al. 2014) Building extraction or detection is one of the important topics for urban area studies. Many studies have been carried out to extract buildings using different data types that obtained from passive and active remote sensing sensors. Optical satellite imagery, aerial images, RADAR imagery, LIDAR data, Digital Surface Model (DSM) and Digital Terrain Model (DTM) are mostly used data types in this kind of studies (Haala and Brenner 1999; Li et al. 2014; Rottensteiner and Briese 2002; Sohn and Dowman 2007). Different methods are used for building extraction; Object- based Image Analysis (OBIA), which allows using spectral, contextual, textural and geometric properties of image objects, is one of the preferred methods, especially when working with high-resolution satellite images (Li et al. 2014; Liu et al. 2005; Shrivastava and Rai 2015).

Building height value is an important parameter for 3D urban modeling (Shiode 2000), post-disaster assessment (Brunner et al. 2010) and building period estimation (Salama 2015). Several different methods have been applied for estimation of building height information from remote sensed images or Digital Elevation Model (DEM). One of the used methods is the shadow-based building height estimation using satellite images (Shao et al. 2011; Shettigara and Sumerling 1998). Digital Height Model (also known as normalized DSM $(\mathrm{nDSM}))$ which is the difference between DSM and DTM is one of the used methods for building height extraction (Haala and Brenner 1999; Yu et al. 2010).

Last decades, one of the new remote sensing platform Unmanned Aerial Vehicle (UAV), gives valuable data source for mapping, 3D modeling, and land use/land cover studies (Nex and Remondino 2014). It is possible to obtain number of informations for urban areas using DSM, DTM and Orthomosaic data generated from UAV images. Building boundary, building height, roads, trees which belong to urban area can be extracted using these data.

In this paper, the possibilities of obtaining the building heights, which are used in estimation of building periods from UAV based data, have been investigated. The investigations were carried out in 3 stages; (i) Building boundary extraction with OBIA, (ii) height calculation for buildings of interest from nDSM and accuracy assessment with terrestrial survey. (iii) Estimation of building period using height information. 


\section{MATERIAL}

\subsection{Study Area}

As a study area in this paper, a small area that includes residential reinforced concrete buildings in the city center of Eskisehir (Turkey) was selected. The study area contains buildings, trees, roads, green area and cars. The buildings have different height values and different dwelling types such as adjoined or detached orders (Figure 1).

\subsection{Specifications of UAV System}

The aerial image collection for the study area was performed with fixed wing Sensefly eBee UAV systems. The UAV contains 16 megapixel RGB digital camera and it has been controlled with Emotion - 2 flight management software that used for flight planning, simulation, flight control and preparation of images for post-processing. The UAV cruise speed changes between $40 \mathrm{~km} / \mathrm{h}$ to $90 \mathrm{~km} / \mathrm{h}$ and it has up to $45 \mathrm{~km} / \mathrm{h}$ wind resistance. The UAV system is $0.7 \mathrm{~kg}$ with 96 $\mathrm{cm}$ wing span. Its flight time capability is nearly 50 minutes for single flight.

\subsection{Aerial Image Collection}

The aerial images for the study area were collected in single flight. The flight was planned with $80 \%$ lateral overlap and $75 \%$ longitudinal overlap with $5 \mathrm{~cm}$ ground sample distance (GSD). Images were taken nearly 160 meters altitude above the ground. Totally 146 images were taken. Before the flight 7 ground control points (GCP) were located in the study area. GCP coordinates were measured with RTK-GNSS systems.

\subsection{Data Processing}

The data processing in this paper, was performed using Pix4D Desktop software. As a result, a $5 \mathrm{~cm}$ resolution orthomosaic and DSM of the study area was produced. Also, $25 \mathrm{~cm}$ DTM was generated for the study area. Figure 1 shows the orthomosaic images of study area.

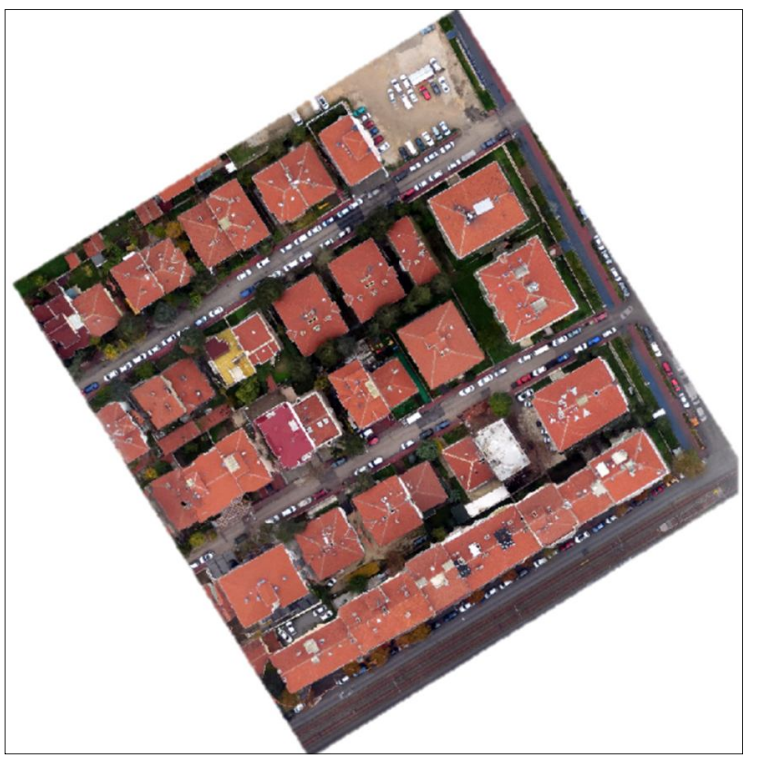

Figure 1: Orthomosaic images of the study area

\section{METHODOLOGY}

The methodology applied in this study consists of three stages; (i) Object based building extraction, (ii) building height extraction, and (iii) building period estimation. Figure 2 indicates the main steps and sub-steps of applied methodology.

\subsection{Object Based Building Extraction}

Pixels in a high-resolution data have a heterogeneous structure, thus, when they are used in classification many meaningless pixels are generated into the class. Object Based Image Analysis (OBIA), which is consist of image segmentation and classification of image objects, gives more advantageous solutions for analysis of high-resolution images. In OBIA, image pixels are meaningfully grouped into homogeneous images objects and noise is consequently reduced ( $\mathrm{Lu}$ et al. 2011). The UAV data used in this study has ultra-high spatial resolution. Therefore, OBIA was preferred method for buildings extraction.

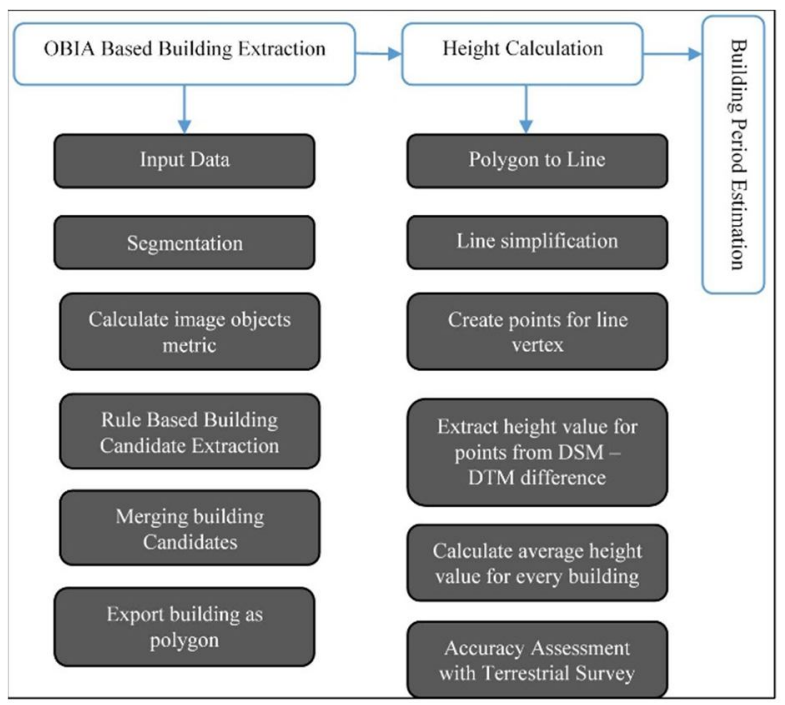

Figure 2. Applied methodology in this study

3.1.1 Image Segmentation: Image segmentation, which is used to generate homogenous image objects, is the first step of object based images analysis. There are several methods for remote sensing applications (Dey et al. 2010). In this study, Multiresolution segmentation (MRS) that is one of most used method in high-resolution image analysis was used for generating homogenous image objects. For obtaining optimum image object size in MRS, several parameters should be determined by users; scale, shape, compactness and layer weight. In this paper, parameters were determined with trial - error methods.

3.1.2 Image Object Classification: Classification is the second step of OBIA. In this step, obtained image objects in segmentation phase attend to relate to classes (Lang 2008). This process can be performed using classification methods such as machine learning algorithms or rule based classification, which has been used for extraction of building polygons in image objects in this study.

Before the classification of the image objects, object metrics which were used at rulesets developing were calculated. For eliminating the ground objects such as cars, roads, gardens, etc., $\mathrm{nDSM}$ was used. 
Brightness value (B) (Eq. 1) and Excess green index (EGI) (Eq. 2) were used to separate trees from buildings objects (Woebbecke et al. 1995).

$$
\mathrm{B}=\frac{1}{\mathrm{n}_{\mathrm{vis}}} \sum_{\mathrm{i}=1}^{\mathrm{n}_{\mathrm{vis}}} \overline{\mathrm{c}}_{\mathrm{i}(\mathrm{vis})}
$$

Where, $\mathrm{B}$ is Brightness value, which is calculated as the sum of objects means in visible band $\left(\overline{\mathrm{c}}_{\mathrm{i}(\mathrm{vis})}\right)$ divided by number of the corresponding bands $\left(\mathrm{n}_{(\mathrm{vis})}\right)$.

$$
\mathrm{EGI}=2 * \text { Green }- \text { Red }- \text { Blue }
$$

Where, Green, Red and Blue are spectral bands of the orthomosaic.

For extracted the buildings from the images objects, Red Blue Spectral Index (RBSI) was used (Eq. 3). This spectral index is more useful for our study area, because nearly all buildings have brown coloured roofs, which give high spectral reflectance in Red band and low spectral reflectance in Blue band.

$$
\text { RBSI }=\frac{\text { Red-Blue }}{\text { Red }+ \text { Blue }}
$$

After segmentation of the layers, some image objects which have high slope value between ground and buildings were generated. Elimination of these kind of objects was done using standard deviation of slope which was obtained from DSM.

\subsection{Building Height Extraction}

There are two dwelling types in the selected urban area. One of them is adjoined dwelling type in which the buildings are attached to each other. The other one is detached type in which the buildings are separately located in the area. In the adjoined buildings, the buildings' vibrations influence each other and it is very hard to distinguish the fundamental vibration period of each building. Therefore, detached buildings were chosen for the building height extraction and the building period estimation in this study.

Building heights were obtained from nDSM data (Eq. 4) (Haala and Brenner 1999; Yu et al. 2010). Extracted buildings polygons using OBIA include all area of building roof. It is possible to get an average building height from $\mathrm{nDSM}$ using these polygons. However, the roof height (h) is not considered for building period estimation. The height which should be considered for building period estimation is the building height $(\mathrm{H})$, which is measured from the ground to the beginning of the roof (figure 3 (a)). Therefore, the height of the roof edges was obtained to find the approximate height values of the building body. For this process, firstly, building polygons features were converted to line and then line simplification was done. After that, points objects were created for vertex of the line. Height values for all points were extracted from nDSM data. Finally, building heights which were used to estimate building periods were calculated as the average of the heights of the points forming the building (Eq. 5).

$$
\text { nDSM= DSM }- \text { DTM }
$$

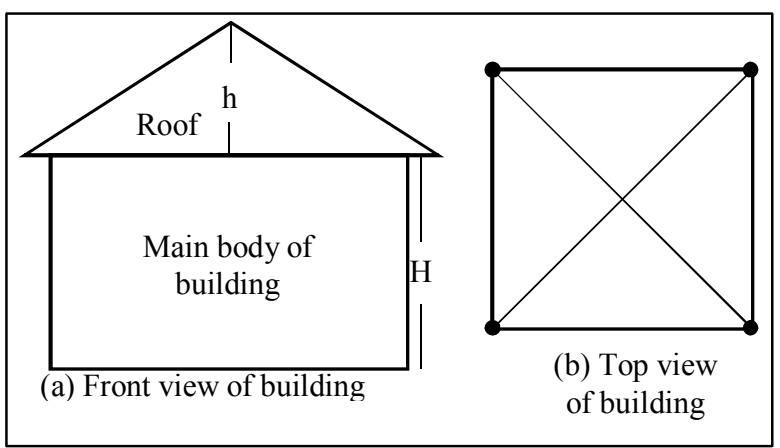

Figure 3. Illustration of a building.

In Figure 3, $\mathrm{H}$ value stands for the building body height. $\mathrm{h}$ value represents the roof height. Black dots represent the intersection of the building boundary lines.

$$
\mathrm{H}_{\mathrm{avg}}=\frac{\sum_{\mathrm{i}=0}^{\mathrm{n}} \mathrm{H}}{\mathrm{n}}
$$

Where, $\mathrm{H}_{\text {avg }}$ is the average of the building body height which is calculated as the sum of the points heights $(\mathrm{H})$ forming the building divided by a number of corresponding points (n).

3.2.1 Accuracy Assessment: As an accuracy assessment, the obtained height values with the applied method in this study were compared with terrestrial survey results. Eight buildings heights were extracted and these building heights were measured with laser distance meter at the field.

\subsection{Building Period Estimation}

A number of simplified equations that relate the height of a building to its fundamental period of vibration are available in many seismic design codes. Most of these equations have been developed for the force-based design of a new building. However, the aim of this study is to assess the seismic performance of existing buildings in the study area. The building period, which should be used in the seismic performance assessment, is the yield period. In this study, the equation (Eq. 6) proposed by Crowley and Pinho (Crowley and Pinho 2004) has been used for the estimation of the yield period of a building.

$$
\mathrm{T}_{\text {yield }}=0,1 \mathrm{H}
$$

Whereas, $\mathrm{T}_{\text {yield }}$, is the yield period of the building in seconds (s). $\mathrm{H}$, is the building height in meters (m). 


\section{RESULTS AND DISCUSSIONS}

\subsection{Object Based Buildings Extraction}

4.1.1 Segmentation: The segmentation and building extraction with OBIA were performed in eCognition Developer 9.0 software. During MRS steps Red (R), Green (G), Blue (B) band of orthomosaic and DSM data were used as input layers. Using only the RGB bands for the segmentation, caused some building roof misleading from the ground objects which have similar spectral features on rooftops. Therefore, DSM layer was used to prevent this problem. After several trial - error steps, optimum parameters for segmentation were determined as scale 50, shape 0.3 , compactness 0.5 . Also equal layer weight was given all input data. Since the UAV data is ultra - high resolution data, it is not possible to get buildings with one objects. Hence, one building was segmented more than one image objects, named as building candidates (Figure 4). After segmentation steps, building candidates were merged to get final shape of buildings.

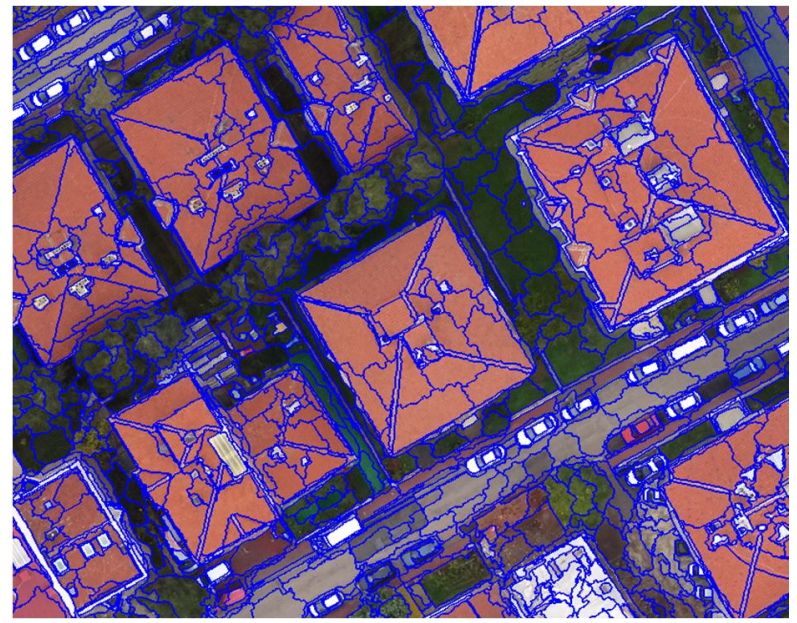

Figure 4. Created images objects with the MRS
4.1.2 Image Object Classification: During image object classification steps, firstly, ground objects were eliminated from all images objects using nDSM layer mean value. Before the calculation of nDSM, the DTM data was resampled at the resolution of DSM. Image objects with $\mathrm{nDSM}$ value $\leq 5$ meter were classified as grounds objects, which includes roads, cars, gardens and small trees, and were eliminated from the building extraction. Secondly, big trees were separated from remaining images objects using mean value of Brightness and EGI parameters. Image objects with mean brightness value $\leq 130$ and mean EGI value $\geq 0$ were classified as big trees objects. Thirdly, images objects that belongs the buildings extracted using mean value of RBSI. image objects with mean RBSI value $\geq 0.36$ were extracted as building candidates. These buildings objects include several image objects, which are between building and ground, and had higher slope values. For elimination of these objects standard deviation of slope value was used. Image objects with standard deviation of slope value $\geq 200$ were separated from the building objects candidates. Finally, image objects that were classified as building candidates were merged into single image object in order to extract the final border of the buildings. The obtained building objects were then exported as polygons features. Final buildings that were extracted with OBIA are shown in Figure 5. In this study, building period estimation was made only for detached buildings. Those buildings are shown with red colour in figure 5 .

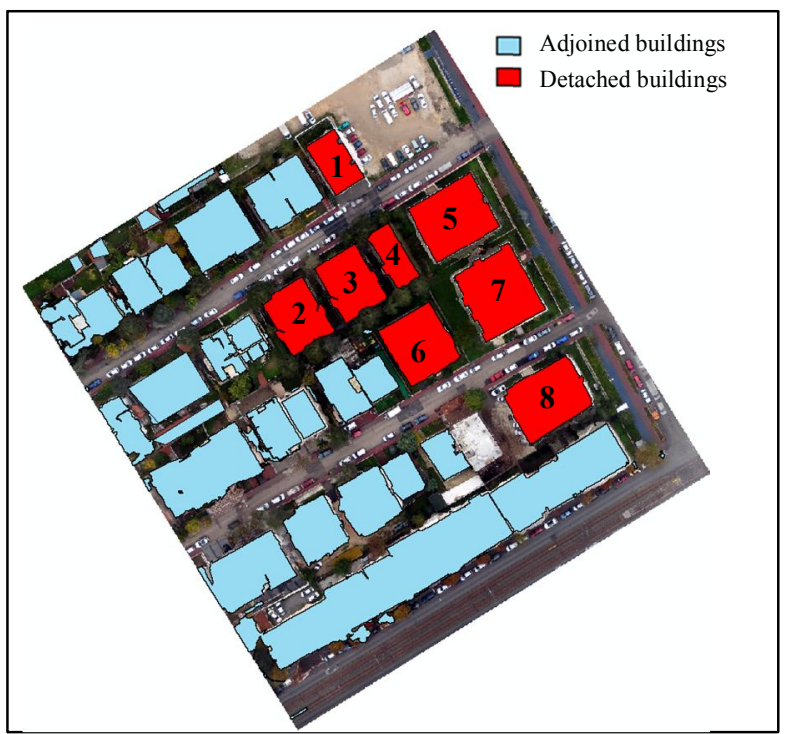

Figure 5. Extracted buildings with OBIA.

\subsection{Building Height Extraction}

Building extraction process was done only for the detached buildings using ArcGIS Desktop 10.3 software. Firstly, building polygon features were converted to line features (Figure 6a). Secondly, line simplification was performed. Because the UAV data has $5 \mathrm{~cm}$ meter resolution, building boundaries, which were extracted with OBIA, has many edges. Line simplification is required to get the actual building shape. In this study, building boundary line was simplified using edge distance $\leq 0.4$ meter value (Figure $6 \mathrm{~b}$ ). Thirdly, points were generated for the line vertexes. Finally, points heights were extracted from $\mathrm{nDSM}$ and average building heights were calculated for every detached building. 


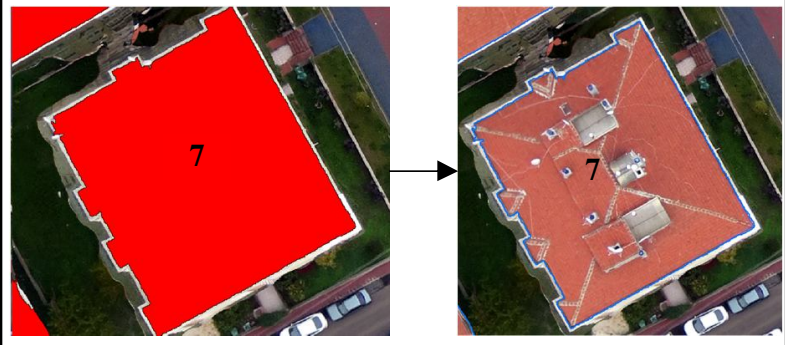

(a) polygon to line conversion

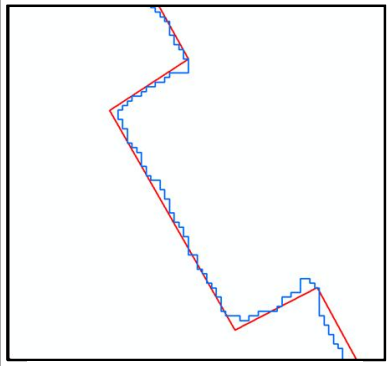

(b) line simplification

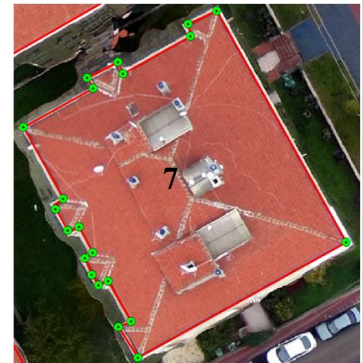

(c) point generation for building line vertexes
Figure 6. Building height extraction steps from $\mathrm{nDSM}$

4.2.1 Accuracy Assessment: Obtained building height results were compared with field based measurements. Table 1 shows the building heights difference between applied methodology and field measurement results. According to results, the maximum height difference occurred in building 2. When we examine the building 2 , three sides of the building are surrounded by trees. The forth side is more shadowed area, thus in cases like this difference in the results can be expected. Since aerial images that are taken from UAV are optical images, the presence of shadowed area and more vegetation cover areas, does not allow generation of highly accurate DTM. Due to the lack of low ground point generation during dense point cloud production.

\begin{tabular}{|c|c|c|c|}
\hline $\begin{array}{c}\text { Building } \\
\text { Number }\end{array}$ & $\begin{array}{c}\text { Applied } \\
\text { Methodology } \\
(\mathrm{m})\end{array}$ & $\begin{array}{c}\text { Field } \\
\text { measurement } \\
(\mathrm{m})\end{array}$ & $\begin{array}{c}\text { Difference } \\
(\mathrm{m})\end{array}$ \\
\hline $\mathbf{1}$ & 14.64 & 14.02 & 0.62 \\
\hline $\mathbf{2}$ & 11.37 & 9.99 & 1.38 \\
\hline $\mathbf{3}$ & 9.92 & 10.07 & -0.15 \\
\hline $\mathbf{4}$ & 10.71 & 10.1 & 0.61 \\
\hline $\mathbf{5}$ & 21.55 & 21.1 & 0.45 \\
\hline $\mathbf{6}$ & 14.63 & 15.13 & -0.50 \\
\hline $\mathbf{7}$ & 20.85 & 21.12 & -0.27 \\
\hline $\mathbf{8}$ & 19.25 & 18.77 & 0.48 \\
\hline
\end{tabular}

Table 1. Obtained and measured building heights and their differences.

\subsection{Building Period Estimation}

In this part of the study, the height data retrieved from object based building height extraction were used to estimate the building periods $\left(\mathrm{T}_{\text {yield }}-\mathrm{UAV}\right)$. Additionally, the building periods were also estimated with respect to the heights from obtained from the field measurements $\left(\mathrm{T}_{\text {yield }}\right)$. Table 2 shows the period results and the differences between these two periods.

\begin{tabular}{|c|c|c|c|}
\hline $\begin{array}{c}\text { Building } \\
\text { Number }\end{array}$ & $\begin{array}{c}\text { (a) } \mathbf{T}_{\text {yield }}-\mathbf{U A V} \\
\text { (s) }\end{array}$ & $\begin{array}{c}\text { (b) } \mathbf{T}_{\text {yield }} \\
\text { (s) }\end{array}$ & $\begin{array}{c}\text { Difference } \\
\text { (a-b)/b } \\
(\%)\end{array}$ \\
\hline $\mathbf{1}$ & 1.464 & 1.402 & 4.42 \\
\hline $\mathbf{2}$ & 1.137 & 0.999 & 13.81 \\
\hline $\mathbf{3}$ & 0.992 & 1.007 & -1.49 \\
\hline $\mathbf{4}$ & 1.071 & 1.010 & 6.04 \\
\hline $\mathbf{5}$ & 2.155 & 2.110 & 2.13 \\
\hline $\mathbf{6}$ & 1.463 & 1.513 & -3.30 \\
\hline $\mathbf{7}$ & 2.085 & 2.112 & -1.28 \\
\hline $\mathbf{8}$ & 1.925 & 1.877 & 2.56 \\
\hline
\end{tabular}

Table 2. Estimated periods and their differences

As it is shown in Table 2, the maximum difference between the periods estimated according to the heights obtained from field measurements and from the UAV data is $13.2 \%$ and the average difference is $2.86 \%$. These values can be considered as reasonable in building period estimation for seismic performance assessment of existing buildings.

\section{CONCLUSION}

The aim of this study was to estimate the buildings vibration periods using building height data obtained from UAV. The results show that the period values, which were estimated according to the heights, retrieved from the UAV data and from the field measurements are highly correlated. Calculating the building heights from the UAV data is more practical than measuring the building heights in the field. Results of this study have shown that the building heights obtained from the UAV data can be used for the building period estimation in the urban scale vulnerability assessment studies. For future study, the used methodology is planned to be applied to a bigger study area.

\section{REFERENCES}

Brunner, D., Lemoine, G., \& Bruzzone, L. (2010). Earthquake damage assessment of buildings using VHR optical and SAR imagery. IEEE Transactions on Geoscience and Remote Sensing, 48, 2403-2420

Crowley, H., \& Pinho, R. (2004). Period-height relationship for existing European reinforced concrete buildings. Journal of Earthquake Engineering, 8, 93-119

Dey, V., Zhang, Y., \& Zhong, M. (2010). A review on image segmentation techniques with remote sensing perspective

Goel, R.K., \& Chopra, A.K. (1997). Period formulas for moment-resisting frame buildings. Journal of Structural Engineering, 123, 1454-1461

Haala, N., \& Brenner, C. (1999). Extraction of buildings and trees in urban environments. ISPRS Journal of Photogrammetry and Remote Sensing, 54, 130-137

Lang, S. (2008). Object-based image analysis for remote sensing applications: modeling reality-dealing with complexity. Object-based image analysis (pp. 3-27): Springer

Li, W., Wang, S., \& Li, J. (2014). Object based building extraction by QuickBird image for population estimation: A case study of the City of Waterloo. In, Geoscience and Remote Sensing Symposium (IGARSS), 2014 IEEE International (pp. 3176-3179): IEEE 
Liu, Z., Wang, J., \& Liu, W. (2005). Building extraction from high resolution imagery based on multi-scale object oriented classification and probabilistic Hough transform. In, Geoscience and Remote Sensing Symposium, 2005. IGARSS'05. Proceedings. 2005 IEEE International (pp. 2250-2253): IEEE

Lu, P., Stumpf, A., Kerle, N., \& Casagli, N. (2011). Objectoriented change detection for landslide rapid mapping. Ieee Geoscience and Remote Sensing Letters, 8, 701-705

Masi, A., \& Vona, M. (2009). Estimation of the Period of Vibration of Existing RC Building Types Based on Experimental Data and Numerical Results. In (pp. 207-225). Dordrecht: Springer Netherlands

Nex, F., \& Remondino, F. (2014). UAV for 3D mapping applications: a review. Applied geomatics, 6, 1-15

Rottensteiner, F., \& Briese, C. (2002). A new method for building extraction in urban areas from high-resolution LIDAR data. International Archives of Photogrammetry Remote Sensing and Spatial Information Sciences, 34, 295301

Salama, M.I. (2015). Estimation of period of vibration for concrete moment-resisting frame buildings. HBRC Journal, $11,16-21$

Salameh, C., Guillier, B., Harb, J., Cornou, C., Bard, P.-Y., Voisin, C., \& Mariscal, A. (2016). Seismic response of Beirut (Lebanon) buildings: instrumental results from ambient vibrations. Bulletin of Earthquake Engineering, 14, 27052730

Shao, Y., Taff, G.N., \& Walsh, S.J. (2011). Shadow detection and building-height estimation using IKONOS data. International journal of remote sensing, 32, 6929-6944

Shettigara, V., \& Sumerling, G. (1998). Height determination of extended objects using shadows in SPOT images. Photogrammetric Engineering and Remote Sensing, 64, 3543

Shiode, N. (2000). 3D urban models: Recent developments in the digital modelling of urban environments in threedimensions. GeoJournal, 52, 263-269

Shrivastava, N., \& Rai, P.K. (2015). An object based building extraction method and classification using high resolution remote sensing data/O metoda de extragere a cladirilor orientata obiect si clasificare folosind date de înalta rezolutie furnizate de teledetectie. In, Forum Geografic (p. 14): University of Craiova, Department of Geography

Sohn, G., \& Dowman, I. (2007). Data fusion of highresolution satellite imagery and LiDAR data for automatic building extraction. ISPRS Journal of Photogrammetry and Remote Sensing, 62, 43-63

Woebbecke, D.M., Meyer, G.E., Von Bargen, K., \& Mortensen, D. (1995). Color indices for weed identification under various soil, residue, and lighting conditions. Transactions of the ASAE, 38, 259-269

Yu, B., Liu, H., Wu, J., Hu, Y., \& Zhang, L. (2010). Automated derivation of urban building density information using airborne LiDAR data and object-based method. Landscape and Urban Planning, 98, 210-219 